Article

\title{
Exploring How Influencer and Relationship Marketing Serve Corporate Sustainability
}

\author{
Carmen Berne-Manero * and Mercedes Marzo-Navarro \\ Department of Marketing, University of Zaragoza, 50005 Zaragoza, Spain; mmarzo@unizar.es \\ * Correspondence: cberne@unizar.es; Tel.: +34-976-762-721
}

Received: 28 April 2020; Accepted: 24 May 2020; Published: 27 May 2020

\begin{abstract}
Influencer marketing furthers the goals of relationship marketing. Companies use influencers to advertise their products through social networks such as Instagram. This digital advertising is aimed at shifting the company's goals from customer acquisition to retention and commitment. While several articles provide interesting advances analyzing social media and sustainability goals, research about influencer types and their impact on engagement preserving corporate sustainability is limited. Thus, the objectives of this study are: (1) Select general influencer traits as positive characteristics in promoting a product; (2) analyze them for micro and macro influencer scenarios; (3) explore potential differences in their adequacy determining customer engagement and preserving corporate sustainability. Credibility, pleasantness, and emotions are the criteria analyzed through multivariate analysis applied over two independent samples of followers. Pleasantness and appearance in the macro influencer scenario and perceived integrity in that of the micro influencer appear to conflict with the desired transparency of the message, while transmission of emotions plays an essential role in both scenarios. This is a very important finding. Companies should assess candidate influencers' emotional projection skills, in addition to evaluating the brand sponsorship costs and defining the target audience for the advertisement, always under the premise of preserving corporate sustainability.
\end{abstract}

Keywords: corporate sustainability; credibility; emotions; engagement; Instagram; macro-microinfluencer; pleasantness; relationship marketing

\section{Introduction}

According to the Association of National Advertisers, the focus of influencer marketing is to leverage individuals with influence over potential buyers and orient marketing activities around these individuals to deliver a brand message to the wider market through social networking channels and collaboration with opinion leaders [1,2]. The same source defines "relationship marketing" as the use of consumer-segmentation and loyalty-building strategies oriented towards building a lasting interactive relationship between the company and its target audience. Many variables and basic keywords apply to both these marketing techniques [3].

Social networks are a type of social media; that is, Internet and Web 2.0 applications, which enable the creation and sharing of user-generated content. This includes ephemeral uploads, such as photos and short videos, as well as live streaming [4]. Rapid digitization has increased consumer involvement, and social media users and businesses exploit this reality to conduct online promotions. This increases access to brand/product information, thereby turning the information search into a key stage of the shopping decision process [5]. Thus, social networks are furthering relationship marketing goals [6-8] and influencing the shape of online relationship marketing [9].

Consumers, who use social networks such as Instagram, Facebook, LinkedIn, and Twitter to connect with their peers, expect the same degree of interactivity with companies [10-12]. Social 
media platforms enable faster and more effective strategic implementation [10] and facilitate brand sponsorships through influencers [13], who are widely acknowledged leaders of opinion and key brand prescribers. Sixty-eight percent of social network users follow influencers in Spain, mainly through Facebook and Instagram, the latter having increased by 35\% in 2019 from the previous year. Social networks are mainly used with sale goals $-79 \%, 67 \%$ of increment since last year-and promotions are the most generated content $(83 \%)$, the one with the most interactions, and the highest traffic [14]. While the majority are macro influencers, defined as those with over 100,000 followers, $60 \%$ of online marketers are also promoting goods through micro influencers and, according to the IAB Spain, the phenomenon is on the rise [14].

Social media advertising is indeed expanding at a rate of over $20 \%$ per year [15] and, here, Instagram plays an essential role. Nevertheless, online advertising is being criticized as a growing nuisance by Net surfers [16]; consumer perceptions of online advertising are deteriorating; and advertisers are starting to question the effectiveness of social media ads while beginning to understand that a constant deluge of intrusive commercial information is no way to guarantee consumers' attention [17]. Meanwhile, it is the responsibility of marketing managers to ensure the smooth running of their social networks and the various processes involved in developing and strengthening customer relationships [18].

Against this background, it is worth exploring the origins of this phenomenon and whether it is compatible with the desired aims of corporate sustainability. Two essential issues emerge in this scenario, both relating to corporate sustainability performance [19]. One is the difficulty of determining the rate of return on investment in brand promotion; that is, assessing (financial) sustainability performance and the profitability of influencer marketing. Gupta and Kumar [20] agree with business researchers that indicate the economic dimension of sustainability as the most desirable because it provides financial strength and avoids conditions leading to an early demise of the business due to financial reasons. The other is the issue of non-financial environmental, social, and governance sustainability performance, including, for example, the avoidance of fake news from fake influencers with fake followers. Business organizations worldwide are expected to utilize their available technological resources to pursue profit-with-purpose by maximizing the return on shareholders' investment, while also achieving social and environmental gains. It is therefore important to identify the value added by influencer marketing in terms both of investment returns and non-financial sustainability enhancement. One way for companies to balance both kinds of sustainability might be through the careful selection of influencers, based on their achievements in terms of user engagement. Market-based measures complement accounting measures by providing deeper insights into corporate performance and incorporating future performance expectations [21].

Social media ads have commercial objectives rather than direct sustainability objectives. However, they all represent the company, and therefore it is in its interest to preserve its corporate sustainability. Several specialized articles explore social media and sustainability goals, mainly the creative elements of digital promotion [22,23], and brand sustainability [19,20,24-26]. Recent articles are addressed to relate influencer marketing, media communication, and sustainability $[27,28]$. Nevertheless, influencer marketing research is still limited [7,29]. Particularly, it is needed to gain insight into people's perceptions of how different types of posts and influencers affect people's responses to influencer marketing, the influencer, and the brand/product [30].

To the best of our knowledge, there is no academic research focused on the potentially different roles played by macro and micro influencers impacting on social network users' engagement with promoted products when it comes to preserving corporate sustainability. To fill this gap, the objectives of this study are (1) to identify distinctive traits of social media influencers useful for their ranking; (2) to analyze how they work according to the type of influencer: Micro and macro; (3) to explore their potential differences as determinants of users' engagement—achieved through the digital advertising, preserving corporate sustainability.

The remainder of this paper is structured in three sections. The first offers a review of the specialized literature on the key concepts involved in the study; that is, influencer marketing (through 
social media), corporate sustainability, and engagement, and how these are related. Section 2 formulates a number of research questions and propositions, and develops an empirical model for testing the respective roles of micro and macro influencers. The final section presents the academic and managerial implications of the results, acknowledges the limitations of the study, and outlines possibilities for future research. The model, tested on two independent samples using multivariate analysis techniques, enables us to identify emotions as one of the essential criteria when addressing corporate sustainability management concerns.

\section{Corporate Sustainability, Influencer Marketing, Engagement, and Instagram}

Sustainability stems from an awareness of the modes of living or thinking and the mindsets which govern our actions and influence our behavior [19]. Corporate sustainability, which involves both financial and non-financial issues, presents not only opportunities, but also certain risks for businesses. Financial activities impact on economic sustainability, which is based on economic prosperity and development [31]. Alshehhi et al. [21] provide a review of competing theories on the impact of sustainability on corporate financial performance. Non-financial activities lead towards environmental, social, and governance sustainability that will protect the interests of shareholders and other stakeholders. In this context, leadership sustainability, which is the process of leading others towards a common vision [32] and is characterized by the ability to coincide with the organizational culture (corporate sustainability) [33], is concerned with the management of corporate resources and depends on the leader's own actions and how they influence others [34].

Social media influencers are opinion leaders that communicate with a sizeable social network of people following them [7]. They maintain a permanent link with their followers, with whom they share their lifestyle, tastes, and hobbies, thus shaping and spreading trends [8]. Ultimately, influencer marketing is increasingly gaining the interest of advertisers [30], and influencers constitute an important promotional tool due to their trend-setting ability and influence on consumption. Intermediaries, agencies, and platforms manage the search, selection, and relationships between brands and influencers. For many companies, managing relationships with social media influencers is an essential marketing strategy [29,35]. The American Association of National Advertisers revealed in April 2018 that marketers are expected to spend about 101 billion dollars on influencer campaigns in 2020 [36].

According the view of the Commitment-Trust Theory, companies adopt influencer marketing strategies with the aim to build positive relationships with consumers by promoting customer engagement [37]. Organizations use social media influencers to attract potential customers and encourage them to engage with the brand. The pursuit of this line of research is the key to understanding how influencer and relationship marketing can enhance sustainability while also increasing the efficiency and effectiveness of social network ad campaigns. A recent study [4] is among the first to present an approach to addressing the effectiveness of social media advertising. The authors examine the impact of Instagram and Facebook advertising on consumer attitudes, ad intrusiveness, and customer loyalty intentions. Their results assert that Instagram Stories create a positive consumer attitude toward ads, but are perceived as more intrusive when compared with Facebook Wall.

The potentially high level of customer engagement in response to a marketing stimulus is a reflection of the effectiveness of the company's marketing strategies. It transcends the moment of purchase and is the product of informal mechanisms, such as word of mouth or personal recommendations. It contributes to value creation and brand image enhancement, as well as customer acquisition [38,39]. Many companies see customer engagement as a way to create, develop, and enrich their customer relationships and achieve business performance gains. This view matches that of authors such as Van Doorn et al. [40] and Kumar et al. [41], who summarize it as the various customer actions that influence business performance. These include both direct actions, such as purchases, and indirect actions, such as customer suggestions or conversations with the company through the social media. To these, Vivek et al. [42] add the degree of customer participation in commercial offers and activities. Pansari and Kumar's [43] view is that achieving customer satisfaction is not enough; 
that, in order to gain a sustainable competitive advantage in building relationships with customers, a company needs to arouse the emotions that lead to commitment. Thus, business objectives extend beyond customer retention to customer relations based on engagement, the promotion of which makes it easier to balance financial and non-financial corporate sustainability goals.

Customer engagement relationships have been greatly facilitated by advancements in information technology over the last 20 years, during which users have shifted from a passive to an active role by using the Internet and Web 2.0 tools to create and share information [6], thereby becoming co-creators of content [10-12]. The social media drive user engagement [8]. Influencer marketing is therefore highly effective. McKinsey Company [44] shows that influencers' product recommendations feed consumer confidence and encourage follow-up by making marketed products appear more genuine and accessible, thereby driving customer engagement [1] and attracting more profitable customers [8].

The most common form of influencer marketing relies on social media such as Instagram [45], with one billion users around the world in January 2020 [46]. 85\% (72\% in 2018 and 68\% in Spain in February 2019 [14]) of social media users declare themselves followers of some influencer. Instagram offers companies outstanding potential in this respect [47]. Instagram is also the fastest growing social network [48], with more than one million advertisers [49]. It is focused on simplicity and high quality visual content [50] with a longer shelf life [47].

Increasingly, information is more compellingly conveyed from brands to consumers through images [51] posted on social networks [50-52]. This visual brand content is more effective at capturing consumer attention [53]; and research by Bergström and Bäckman [54] provides evidence of Instagram's success for sharing product information and boosting consumer engagement. This has been confirmed by Rhythm One Report [55], where Instagram is associated with greater social profitability, a higher mean engagement rate, higher return on investment, a higher ratio of social participation to total exposure, and a wider target audience.

Despite this recognition, $70 \%$ of posts remained unseen [56], which could indicate a degree of saturation and a need for clearer differentiation through the identification of issues that require consideration in influencer selection processes. Accurate selection of opinion leaders is a question of interest [57], and it should be based on balancing both the associated costs and the potential of the chosen candidates protecting corporate sustainability. The usual influencer classification criteria, however, are quality of content, the number of followers, and prestige, moreover age, location, gender, occupation/industry, and interest/hobbies. The number of followers is the most widely used, because it is an indication of the influencer's network size and popularity [7]. Thus, there are four kinds of influencers: Mega, macro, micro, and nano, depending on their number of followers. Macro and micro are the most commonly used by companies with commercial goals. An unofficial but widely used classification assigns macro influencers an audience of between 100,000 to 1,000,000 followers and a more professional profile than that of micro influencers. Due to their popularity, they also require less selection and management time, and carry less risk of fake followers. However, they are also more expensive, and may generate distrust by appearing unnatural. Micro influencers, on the other hand, while being opinion leaders, have between 1000 and 100,000 followers, and charge less for their services. They are normal persons, who have become known for his or her knowledge about some specialist niche area [58].

\section{Research Questions and Empirical Model}

In order to avoid ineffectiveness, it is important to ensure that the digital advertising message comes from an appropriate source. Therefore, it is interesting to identify some influencer classification criteria that complement those already known. In this sense, previous research provides clues focused on influencer traits. In the social network context, authors such as Edell and Chapman [59]; Yilmaz et al. [60]; Jin and Phua [61]; McLaughlin [62]; and De Veirman et al. [7] emphasize sympathy, credibility, and transmission of emotions as the most important. Interactive web [63] lists authenticity, innovativeness, credibility, interactivity, and transmission of emotional content, while Glucksman [64] 
cites trust, authenticity, and interactivity. Sympathy and credibility have been shown to have a strong impact on the way social media users process advertising messages $[7,60]$, and there is evidence of their positive effect on purchase intention $[65,66]$ through their power of attraction and capacity to generate a positive attitude towards the message and the brand [66-68], which in turn increases the probability of purchase and engagement [69].

The micro influencers on Instagram are thought to achieve a more desirable form of engagement than macro influencers, by adapting the brand promotion effort to a more specific and committed audience, thus reaching new audience niches and obtaining high conversion rates [70]. They appear more natural, and tend to consider their followers as friends [71]. Macro influencers are perceived as being more accessible and socially desirable [61,72,73], and thus more likely to generate consumer sympathy toward a brand and boost its popularity [7]. Therefore, closeness and friendliness, and other sympathy attributes-pleasantness onwards, because it refers to affective experience, more than emotional understanding - are intrinsic to macro and micro influencers, although it is not clear their different potential to generate positive consumer attitudes and behaviors. While a larger number of followers may increase the reach of the message, even further reach may be required.

The credibility of the information source, meanwhile, depends on the trust it inspires in the receiver [74-76]. Morgan and Hunt [37] see trust as one party's confidence in the other's reliability and integrity. Credibility-trustworthiness involves honesty, integrity, and believability of an endorser. Moreover, of expertise: Relevant knowledge, skills, and experience [77]. Credibility effects can be explained by Attribution Theory, a stream of research according to which consumers attribute motives to the sender of the message [78]. The less known the message source, the less its credibility, the less persuasive the arguments [79,80], and the less convinced the consumer [78,81]. As the credibility of the source increases, consumers become more likely to be persuaded by the message $[77,82,83]$. Consequently, influencers with a large number of followers can be perceived as credible and expert endorsers in comparison to influencers with fewer followers. However, other studies claim that micro-influencers connect with their audiences on a deeper level and generate greater engagement. As the number of followers increases, engagement thus tends to decrease [84]. According to Djafarova and Trofimenko [85], social media users consider micro-celebrities to be credible if they follow certain behavioral criteria online, such as being proficient in using the product, responsive to the user, active, smart, and self-presentation.

Moreover, the consumer's ad exposure arouses certain emotions [86]. Consumer commitment grows from customer satisfaction and an emotional attachment to the brand [87]. According to Sashi [88], only closeness and emotional attachment turn a loyal customer into a fan of the product, brand, or business, and only then is engagement achieved. A survey, conducted by influencer marketing agency Whalar in 2019 [89], found that influencer ads are significantly more emotionally intense and memorable than TV ads. The influencer marketing is spun around emotions, relies on the emotional connections between influencers and followers. Thus, both macro and micro influencers must transmit positive emotions, although each might have different abilities.

There are two forms of engagement: Calculative and affective [90]. The first is more rational and driven by lack of choice or change of costs. It drives loyalty and lasting relationships. Affective engagement is driven by trust and reciprocity in a relationship. If customers are both loyal and delighted, that is, if their engagement with the seller is both calculative and affective, the result is a lasting relational exchange based on strong emotional ties $[88,90]$. As the exchange becomes more relational and emotional, bonds strengthen, and customers become advocates for the sellers in their interactions with others, both customers and non-customers [86]. Although they have more followers, macro influencers do not target specific audiences, and their messages may even breed distrust, and thus have less influence on commitment than those of micro influencers.

This raises the following research questions: Are sympathy, credibility, and emotional traits of the influencer capable of determining the level of engagement of the recipient of the advertising message? Are there differences in this regard between macro and micro influencers? 
Based on the literature review, which is not conclusive, and on the research questions, three propositions are presented:

Proposition 1. The perceived pleasantness of the macro and the micro influencer affects positively on customer (follower-recipient of the post) engagement, and this impact could have a different intensity depending on the type of influencer: Micro-macro.

Proposition 2. The perceived credibility of the macro and the micro influencer affects positively on customer engagement, and this impact could have a different intensity depending on the type of influencer: Micro-macro.

Proposition 3. The transmission of emotions by the macro and the micro influencer affects positively on customer engagement, and this impact could have a different intensity depending on the type of influencer: Micro-macro.

Pleasantness, credibility, and emotions are considered to be involved in an empirical model as key determinants of customer engagement. This model differentiates by type of influencer, micro vs. macro, and will be tested in order to answer the research questions and related propositions (Figure 1).

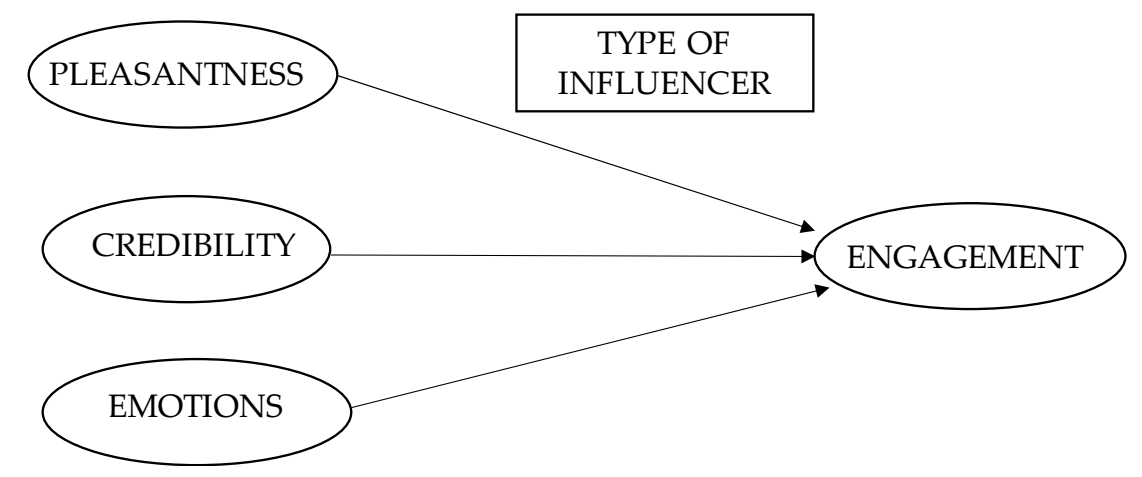

Figure 1. Empirical Model.

\section{Materials and Methods}

This study uses survey data from two structured questionnaires (for macro/micro influencers). Each shows a post with fixed image/s and text. The questions address issues relating to the influencer traits selected: Pleasantness, credibility, and ability to transmit emotions, and respondents' declared levels of engagement and Instagram usage.

The study focuses in particular on Instagram influencers in the beauty industry. Two scenarios are presented, each showing a post for an L'Oreal promotion campaign. The company uses both macro and micro influencers to advertise its product: The "Glow Mon Amour" illuminator, and other complementary products. Most influencers begin by uploading a photo of themselves testing the main product (the illuminator) and follow up with another featuring it alongside other products from the same line. For this particular campaign, the company selected female Instagram influencers (macro and micro), and 78 posts appeared with its hashtag (\#despiertatuluz) For this study, we selected a macro influencer (María Pombo, @mariapombo: Miss Universe Spain 2015, model, and entrepreneur, with over 1.3 million followers, and reported by the Influencer Marketing Hub to earn between 2484 and 4140 Euros per post) and a micro influencer (Marta Baceidero, @martabaceidero: Chic fashion model, travel and lifestyle photo blogger, with just over 50,000 followers). Both posts included \#LorealParisEspaña and \#EmbajadoraLoreal, which identify the influencers as brand ambassadors (influencer under contract with the firm to promote its products), and the post as a commercial disclosure. 


\subsection{Field Work and Sample Description}

The survey was presented through Google Forms as part of a social media research project, and the questionnaire was distributed through Instagram, Facebook, Twitter, and WhatsApp, using the snowball sampling method to reduce selection bias [91] and increase the response rate. The questionnaires were pre-tested on 22 subjects to ensure understanding of the initial instructions and measuring scales, and to estimate required completion time.

After general questions about the use of Instagram, a filter question was included to identify respondents as Instagram users and followers of Instagram influencers. Those that qualified were directed to complete the rest of the survey. The rest of the questions concern the measurement of the variables included in the empirical model. The survey was conducted in two staggered waves; the first to recruit followers of macro Instagram influencers; the second to recruit followers of micro Instagram influencers.

The first wave yielded a total of 462 questionnaires, of which 362 were valid. The second, aimed at followers of micro influencers, was continued until another 362 valid questionnaires were obtained. In all, data collection took around two months, from December (2018) to January (2019).

\subsection{Variable Measurement and Analysis}

The indicators used to measure the model variables were obtained from the literature, which is not conclusive regarding measurement scales. The items dance among the different criteria and dimensions, which is probably due to the differences between the study contexts and cultural environments. Due to the increased use of social networks, users will become increasingly adept, and it can be expected some changes in attitudes and behaviors, which can affect the results of the research. For example, the creation of a digital "new language" could provoke changes in the minds of the individuals and their ways. Being aware of this difficulty, and focusing the selection of indicators on the influencers' role in advertising, pleasantness measurement is based on prior works regarding different contexts, such as Ferran, [92], in the context of social psychology, Whittler and Dimeo [93], in the context of viewer's reaction to racial cues in advertising stimuli, and Yilmaz et al. [60], in the context of effectiveness of print advertisements. Due to the differences between the prior study contexts in this research, the items have been selected carefully with regard to influencer pleasantness. They relate to the traits of friendship and closeness: Friendliness, closeness, sympathy, and niceness. The 11 perceived credibility indicators are based on Morgan and Hunt [37], Lou and Yuan [94], Yilmaz et al. [60], and Ohanian [77], who provides three first-order dimensions correlated: Attractiveness, expertise, and trustworthiness as measurements of credibility in an offline study context. Eight emotion indicators, including enthusiasm, inspiration, entertainment, and tranquility, among others, were selected from those used by Edell and Chapman [59] to explore general advertising effects, although the focus here is on positive effects.

The nine indicators used for customer engagement (including likes, comments, visits to the company/brand website, search for further product information, purchase intention, and brand recall) are based mainly on Kumar et al. [41], Vivek et al. [42], Guidara [56], and Coss [70]. They cover both calculative (rational) and affective commitment. All questionnaire items are measured on a seven-point Likert scale (from 1 "completely disagree" to 7 "completely agree").

The descriptive analysis is followed with mean differences t-test and exploratory factor analysis (EFA) using principal components analysis (PCA). After a reliability check, SPSS 21.0 software is then used to perform a stepwise regression in both scenarios to identify the engagement determinants in each sample and detect any differences. The initial intention to use a multi-sample methodology to test the working hypotheses proved unviable according to PCA results of the dependent variable, engagement, which revealed a different number of components in each sample. Under these circumstances, the analysis methods chosen are adequate [95-97]. 


\section{Results}

Of the total sample, $80.4 \%$ are female and $89.7 \%$ are aged between 18 and 36 . The means and standard deviations (SD) analysis of the Instagram usage indicators reveal average values above the scale mid-point for all except the perception of Instagram influencers as opinion leaders. The highest-scoring indicator (more than 5 points out of 7) was "Instagram is the social network I use most"; and photographic content scores higher (averaging 4.69 points) than video content (see Table 1).

Table 1. Basic statistics: Mean and standard deviation. Total sample.

\begin{tabular}{lcc}
\hline & Mean & SD \\
\hline It is the social network I use most & 5.43 & 1.90 \\
I like brand posts on Instagram & 3.95 & 1.75 \\
I prefer photo posts to video posts & 4.69 & 1.58 \\
The first time I heard of many companies was through Instagram & 4.04 & 1.85 \\
I follow many brands through Instagram & 3.63 & 1.92 \\
I know several Instagram influencers & 4.79 & 2.06 \\
Instagram influencers are my main brand and product opinion leaders & 2.97 & 1.72 \\
I follow more than one Instagram influencer & 4.75 & 2.25 \\
\hline
\end{tabular}

\subsection{Macro Influencer Versus Micro Influencer}

An independent samples t-test comparing followers' opinions of micro vs. macro influencers reveals differences in perceived closeness and friendliness, for which micro influencers are more highly rated, but no significant differences in any other pleasantness indicators (Table 2). This reinforces the idea that micro influencers can compensate for having fewer followers with their ability to reach a more specific audience who prefer a leader who feels closer.

Table 2. Mean differences t-test results: Pleasantness.

\begin{tabular}{lcccc}
\hline & $\begin{array}{c}\text { Macro } \\
\text { Mean }\end{array}$ & $\begin{array}{c}\text { Micro } \\
\text { Mean }\end{array}$ & $\boldsymbol{t}$-Value & Sig. \\
\hline The influencer seems very sympathetic & 4.25 & 4.34 & -0.869 & 0.386 \\
I feel the influencer is very close to me & 3.86 & 4.21 & -3.097 & 0.002 \\
The influencer is very nice to me & 4.27 & 4.38 & -1.011 & 0.313 \\
The influencer looks very friendly & 4.27 & 4.53 & -2.408 & 0.017 \\
\hline
\end{tabular}

Comparison of the credibility indicators reveals significant differences in the mean values for attractiveness, elegance, style, experience, and capability of the influencer, which are higher for macro influencers; and in the mean naturalness scores, which favor micro influencers, as do the mean sincerity scores, with significance close to the 95\% level (Table 3). It appears, therefore, that the perceived credibility of the macro influencer is the result of a more professional personal profile. 
Table 3. Mean differences t-test results: Credibility.

\begin{tabular}{lcccc}
\hline & $\begin{array}{c}\text { Macro } \\
\text { Mean }\end{array}$ & $\begin{array}{c}\text { Micro } \\
\text { Mean }\end{array}$ & $t$-Value & Sig. \\
\hline The influencer is very attractive & 5.41 & 4.33 & 10.055 & 0.000 \\
\hline The influencer is very elegant & 5.15 & 4.22 & 9.720 & 0.000 \\
\hline The influencer is very stylish & 5.37 & 4.26 & 11.498 & 0.000 \\
\hline The influencer projects great reliability & 4.23 & 4.16 & 0.711 & 0.478 \\
\hline The influencer seems very honest & 3.90 & 4.01 & -1.054 & 0.293 \\
\hline The presentation, image, and text appear very sincere & 3.67 & 3.88 & -1.947 & 0.053 \\
\hline $\begin{array}{l}\text { The influencer inspires confidence in the product and } \\
\text { the sponsored brand }\end{array}$ & 4.01 & 3.98 & 0.271 & 0.786 \\
\hline The influencer has a very natural pose in the photos & 3.22 & 4.09 & -7.184 & 0.000 \\
\hline The post illustrates the great experience of this influencer & 4.13 & 3.85 & 2.624 & 0.009 \\
\hline The image and the text complement each other very well & 3.90 & 4.09 & -1.702 & 0.090 \\
\hline The influencer seems very competent & 4.16 & 3.96 & 2.051 & 0.041 \\
\hline
\end{tabular}

The mean values of the emotions indicators are lower in general than those of the two previous criteria, with some failing to reach the midpoint of the measuring scale. The only significant difference in means is for the admiration indicator, which favors the macro influencer (Table 4). The transmission of emotions, therefore, is another challenge for companies wishing to advertise their brand/products.

Table 4. Mean differences t-test results: Emotions.

\begin{tabular}{lcccc}
\hline & $\begin{array}{c}\text { Macro } \\
\text { Mean }\end{array}$ & $\begin{array}{c}\text { Micro } \\
\text { Mean }\end{array}$ & $\boldsymbol{t}$-Test & Sig. \\
\hline The influencer projects great enthusiasm & 3.79 & 3.91 & -1.122 & 0.263 \\
The influencer's presentation of the product and sponsored & 3.45 & 3.52 & -0.716 & 0.474 \\
brand is inspirational & 3.23 & 3.18 & 0.551 & 0.582 \\
I find the influencer's posts very entertaining & 3.65 & 3.67 & -0.211 & 0.833 \\
The influencer projects great tranquility & 3.33 & 3.36 & -0.234 & 0.815 \\
What the influencer tells me seems very credible (informative & 2.70 & 2.32 & 3.738 & 0.000 \\
value of generated content) & 3.42 & 3.53 & -0.934 & 0.351 \\
I really admire this influencer & 3.10 & 3.27 & 1.778 & 0.106 \\
The influencer appears very genuine/authentic & & &
\end{tabular}

The relatively low mean values (maximum 3.18) of the engagement indicators for both samples are striking, the only differences appearing in the intention to share the post and intention to make emoji comments, with the micro influencer prevailing in both cases. Thus, while showing that the company's social networking effort is relatively ineffective at engaging followers, either with the influencer or the brand, the results suggest that the micro influencer has more potential in this respect (Table 5). 
Table 5. Mean differences t-test results: Engagement.

\begin{tabular}{lcccc}
\hline & $\begin{array}{c}\text { Macro } \\
\text { Mean }\end{array}$ & $\begin{array}{c}\text { Micro } \\
\text { Mean }\end{array}$ & $t$-Test & Sig. \\
\hline This post spurs me to interact very actively with the influencer & 2.49 & 2.50 & -0.122 & 0.903 \\
\hline It strongly encourages me to make comments mentioning other people & 2.15 & 2.27 & -1.624 & 0.105 \\
\hline It strongly encourages me to make comments with emojis & 2.04 & 2.22 & -2.602 & 0.010 \\
\hline It directly triggers the impulse to send "likes" & 3.18 & 3.13 & 0.431 & 0.667 \\
\hline It directly triggers the urge to "share" the post & 1.97 & 2.22 & -3.440 & 0.001 \\
\hline It directly triggers the urge to visit the website of the sponsored brand & 2.86 & 2.84 & 0.264 & 0.792 \\
\hline It makes the sponsored brand/product easy to remember & 3.12 & 2.95 & 1.750 & 0.081 \\
\hline It directly triggers the urge to seek further product information & 2.89 & 2.80 & 0.951 & 0.342 \\
\hline I intend to buy the product presented by the influencer & 2.53 & 2.57 & -0.484 & 0.628 \\
\hline
\end{tabular}

Table 6 summarizes the results for each criterion of interest, highlighting those with significantly higher mean values for one or other type of influencer. This simplified view reveals some interesting nuances between their respective roles and effectiveness. The macro influencer, with her wider following, presents a more professionally nuanced profile due to her acquired fame and recognized leadership status, which she appears to have achieved at the cost of proximity, accessibility, and perceived closeness to reality.

Table 6. Most highly rated indicators for each criterion by type of influencer.

\begin{tabular}{ccc}
\hline Criterion & Macro Influencer & Micro Influencer \\
\hline Pleasantness & $\begin{array}{c}\text { Closeness } \\
\text { Friendliness }\end{array}$ \\
\hline Credibility & $\begin{array}{c}\text { Elegance } \\
\text { Style } \\
\text { Experience } \\
\text { Competence }\end{array}$ & Sincerity * \\
\hline Emotions & Admiration & Naturalness \\
\hline Engagement & $\begin{array}{c}\text { Share the post } \\
\text { Make emoji comments }\end{array}$ \\
\hline
\end{tabular}

* Significance level close to $95 \%$.

\subsection{Principal Component Analysis}

The Cronbach's alpha test and Principal Component Analysis (PCA) with Varimax rotation yielded a reliability score greater than 0.7 , which is the minimum recommended by Nunnally [98].

\subsubsection{PCA-Macro Influencer}

The PCA confirms that, concerning the macro influencer, pleasantness constitutes a single component explaining $87.2 \%$ of the total variance. Credibility, meanwhile, has two principal components explaining $71.8 \%$ of total variance. The first, labeled "Integrity", comprises honesty, experience, reliability, capability, naturalness, affinity, trust, and sincerity; and the second, labeled "Appearance", comprises attractiveness, elegance, and style. The transmission-of-emotions is formed by the eight emotion indicators considered and explains $68.3 \%$ of the total variance. Finally, after removal of "likes", following the reliability analysis, the engagement construct is found to have two principal components. The first, which comprises comments to others, use of emojis, interaction with the influencer, and sharing the post, is labeled "Affective Engagement", and concerns the impulse to relate with others, motivated by the post. The second, which comprises additional product information search, website 
visits, brand recall, and product purchase intention, is labeled "Rational Engagement", and concerns decisions leading to direct involvement with the sponsored product. Together, these two components explain $79.7 \%$ of the variance.

\subsubsection{PCA-Micro Influencer}

With respect to how the micro influencer is perceived, the PCA reduces the pleasantness indicators to a single component explaining $77.3 \%$ of the total variance; although the reliability analysis advises the removal of Admiration. Two credibility components explain $82.3 \%$ of the total variance. The first is formed by honesty, experience, reliability, capability, naturalness, affinity, trust, and sincerity, these last three factors having the highest loadings. The second credibility component is formed by elegance, attractiveness, and style. These results are consistent with findings for the macro influencer. The eight transmission-of-emotions indicators also load into one component explaining $77.3 \%$ of the total variance. In contrast to the previous case, engagement for macro influencer followers constitutes a single component, comprising seven indicators (after removal of "likes"), explaining $74.1 \%$ of the total variance (Table 7).

Table 7. Comparison of the principal component analysis (PCA) results by type of influencer.

\begin{tabular}{ccc}
\hline Criterion & Macro-Components & Micro-Components \\
\hline Pleasantness & Pleasantness & Pleasantness \\
\hline Credibility & $\begin{array}{c}\text { Integrity } \\
\text { Appearance }\end{array}$ & $\begin{array}{c}\text { Integrity } \\
\text { Appearance }\end{array}$ \\
\hline Emotions & Emotions & Emotions \\
\hline Engagement & $\begin{array}{c}\text { Affective Engagement } \\
\text { Rational Engagement }\end{array}$ & Engagement \\
\hline
\end{tabular}

\subsection{Stepwise Regression Analysis}

Given that the dependent variable (engagement) behaves differently in each scenario, the Multisampling SEM is replaced with Stepwise Multiple Regression analysis (SRA), thus avoiding potential multicollinearity among the variables and enabling identification of the significant determinants.

\subsubsection{SRA-Macro Influencer}

The SRA between Affective Engagement and macro followers yields a coefficient of determination close to $25 \%$ (adjusted $\mathrm{R}^{2}$ value of $24.7 \%$ ), and shows that affective engagement is negatively related with appearance, and positively related with emotions (Table 8). Rational Engagement is also explained by these two determinants, and the coefficient of determination is similar to the previous one $(24.2 \%$ adjusted $R^{2}$ value) (Table 9). The joint coefficient of determination for both forms of engagement is moderately high (close to 50\%). Overall, the (affective and rational) engagement potential of the macro Instagram influencer is a function of appearance and the capacity to transmit emotions, decreasing with the former and increasing with the latter.

Table 8. Stepwise multiple regression analysis (SRA) results. Macro influencer. Affective engagement.

\begin{tabular}{cccc}
\hline & Beta & $\mathbf{T}$ & Sig. \\
\hline Constant & & 0.000 & 1.000 \\
Emotions & 0.585 & 6.775 & 0.000 \\
Integrity & -0.033 & -0.429 & 0.668 \\
Pleasantness & -0.055 & -0.612 & 0.541 \\
Appearance & -0.169 & -2.771 & 0.006 \\
\hline
\end{tabular}


Table 9. SRA results. Macro influencer. Rational engagement.

\begin{tabular}{cccc}
\hline & Beta & $\mathbf{T}$ & Sig. \\
\hline Constant & & 0.000 & 1.000 \\
Emotions & 0.583 & 6.730 & 0.000 \\
Integrity & -0.025 & -0.328 & 0.743 \\
Pleasantness & -0.073 & -0.810 & 0.419 \\
Appearance & -0.184 & -3.008 & 0.003 \\
\hline
\end{tabular}

\subsubsection{SRA-Micro Influencer}

The SRA in this case yields an adjusted $\mathrm{R}^{2}$ value of $50.8 \%$. All the variables are significant determinants of engagement potential, although the relationship with credibility and pleasantness is negative, while with emotions it is positive (Table 10).

Table 10. SRA results. Micro influencer. Engagement.

\begin{tabular}{cccc}
\hline & Beta & T & Sig. \\
\hline Constant & & 0.000 & 1.000 \\
Emotions & 0.951 & 12.707 & 0.000 \\
Integrity & -0.107 & -2.205 & 0.028 \\
Pleasantness & -0.143 & -2.231 & 0.026 \\
Appearance & -0.162 & -2.167 & 0.031 \\
\hline
\end{tabular}

\section{Discussion}

Commercial ads on social networks with influencers specifically directed towards sustainability objectives are not the most frequent, but corporate sustainability must also be preserved. Therefore, it is important to identify influencer traits that help to achieve these ends and allow the influencer to be classified and selected according to its suitability. In these terms, this research analyzes pleasantness, credibility, and emotions as perceived by recipients of the advertising, in micro and macro influencer scenarios, and reaches important conclusions.

First of all, comparing micro and macro influencer scenarios, the results of the difference of means test show that the macro influencer is perceived as more admirable and more credible through a more polished professional image, while in the micro influencer, it is through closeness, friendliness, and naturalness, all of which are associated with a less slick image and closer affinity with the consumer. The micro scenario also presents higher mean values of interaction, sharing, and comments. Thus, although having fewer followers may reduce micro influencers' potential for attracting stakeholders to the sponsored company, it may mean that they reach a more specific and potentially more dedicated target audience.

With respect to the potential of the three criteria as determinants of customer engagement, the two scenarios present both differences and similarities. In both samples, emotions stand out as positive determinants of commitment, in line with Sashi [88] and Gustaffsson et al. [90], while credibility is made up of integrity and appearance. This grouping does not coincide with that indicated by Ohanian [77], which is not surprising due to the differences between the study contexts and their separation in time. The author warns that this existing scale can be expanded or modified.

In the macro scenario, however, engagement is shown to have two components: Calculative and affective, in line with Gustaffson et al. [90], while in the micro scenario, engagement shows only one component. This makes a significant difference, and reinforces the idea that different leaders (micro vs. macro influencers), different followers. It may be that the followers of micro influencers express their engagement in a less structured, more fluid manner. However, given that the proportions of variance explained are very similar in both scenarios, any differences between micro and macro influencers are not necessarily a reflection of their leadership skills. It should be noted, however, that the parameter 
value for emotions is somewhat higher (less negative) in the micro scenario, which is consistent with the idea that the followers of micro influencers expect more from them as a source of positive emotions.

Another difference is that, in the macro scenario, engagement appears influenced, not only by the transmission of emotions, but also (albeit negatively) by appearance. Thus, attractiveness, elegance, and style work counter to expectations. In the micro scenario, engagement is indeed determined by all the variables considered. However, all except emotions have a negative influence, in contrast with evidence from previous studies, such as Phillips and Lee [65]; Arora [66]; De Veirman et al. [7], although these works are not focused in influencer marketing and social networks. While this negative influence is low (around -0.4 in both scenarios), it might indicate that followers suspect a lack of authenticity behind the influencer's pleasantness, appearance, and even integrity, or that they see a forced attempt at sympathy and credibility, thereby placing these variables in conflict with the desired transparency. In neither scenario should the influencer try too hard to adjust these characteristics, because they appear to be counterproductive.

The main way to motivate engagement is through the transmission of emotions. This, therefore, should be the focus of influencers in their role as ambassadors and prescribers. Even if reduced to this single task, the job is not easy. Influencers, therefore, face a complicated future, and probably need to reinvent their role as opinion leaders and prescribers in commercial ads. In 2019, the Fashion Business reported losses of 1300 million Euros in influencer marketing, largely due to the well-known phenomenon of fake followers. While accepting that effective transmission of emotions can allay consumers' fear of fraudulent practices, the influencer still needs to find the right tools for the purpose. One way to start is with a name change. Some macro influencers claim to feel uncomfortable or unidentified with the term and may already be thinking of a suitable alternative. However, further changes, including more stringent and more uniform rules for social networks, would be required. According to Veronika Heilbrunner (Instagram influencer with 213,000 followers in March 2020), Instagram also needs tighter rules, or it could end up destroying itself. Spain has introduced Autocontrol, an independent body charged with ensuring compliance with advertising codes of conduct. The first time it issued a warning to a (micro) influencer was in January 2020 for failing to alert followers to the fact that a post carried an advertising message, even though the brand in question had paid nothing for it. Submission to Autocontrol is voluntary for those involved in social media advertising. Countries such as France, Italy, United Kingdom, and USA are more advanced in this respect. Although online behavioral intentions are generally low, people are more inclined to share, like, or comment on the post when they recognize it as advertising [30].

This study contributes to the body of academic knowledge about relationship and influencer marketing, commercial advertising, and preservation of corporate sustainability, by (1) selecting three traits (pleasantness, credibility, and emotions) as useful criteria for assessing the role of the Instagram influencer in motivating customer engagement with the advertised brand/product, and therefore, for selecting among influencer alternatives; (2) identifying the unexpected negative relation between pleasantness and credibility with customer engagement, and emotions as an essential criterion to achieve positive customer engagement; (3) identifying credibility and customer engagement as underlying constructs with two components-potential dimensions-each one; (4) showing differences between micro and macro influencer scenarios that worth attention.

Regarding similarities and differences, the capacity to transmit emotions is an essential trait for selecting influencers. This is one of the most valuable findings of this research. The results show moreover that enthusiasm, admiration, inspiration, entertainment, tranquility, the informative value of the content, authenticity, and happiness serve this purpose. Brand/product sponsorship costs and the choice of the target audience for the advertisement are also essential considerations for the pursuit of corporate sustainability. In the macro influencer environment, customer engagement could be considered to be a multidimensional variable; that is, a latent variable reflected in two dimensions: A calculative or rational dimension, closely relating to direct commitment with the advertised brand 
and to economic objectives, and an affective dimension, involving indirect commitment with the brand through relationships with others.

Returning to the propositions, contrary to expectations, it can be seen that the answer to the first two is no: Pleasantness is a determinant of customer engagement only in micro influencers, and then in a negative sense. Thus, it cannot be said that the sympathy evoked by macro influencers gives them greater customer engagement power than micro influencers. Meanwhile, credibility is a negative determinant of customer engagement in both scenarios, which yield very similar estimated parameter values (around -0.3). Hence, there is no difference between the macro and micro scenarios in terms of the relationship between perceived credibility and customer engagement. This result is coincident with the work of Boerman [30] comparing micro- and meso-influencers influencers regarding intentions to engage with the post. Concerning the third proposition, emotions are found to be a positive determinant of engagement in both scenarios, with an estimated parameter value close to 1.0. These results accept the proposal and are coincident with the reported by Pansari and Kumar [43] citing emotions as an essential element of sustainable competitive advantage.

The above confirms the views of Rezaee [19] regarding the difficulty of analyzing the investment/performance ratio with respect to economic (financial) sustainability. Influencer marketing might nevertheless still have a role in preserving financial and non-financial sustainability. One way for companies to balance both forms of sustainability would be through very careful selection of influencers, based on their customer engagement power.

Regarding the managerial implications of this study, therefore, the findings confirm that influencer marketing can be said to serve relationship marketing. Marketing managers, to select the appropriate influencers for the company's marketing strategies, must assess their ability to transmit emotions (the different indicators that this feature includes serve for this proposal), also, to consider cost criteria and business objectives. Further, they must carefully treat pleasantness and credibility traits because they can produce a contrary effect to the expected. In particular, for selecting Instagram macro and micro influencers, three strategic options are available: (1) Generic and less differentiated strategy, (2) addressed and more differentiated strategy, and (3) combining the first two strategies. Communication goals, particularly customer engagement objectives, budgetary availability, product characteristics, and the target market profile are the main considerations when choosing the most effective corporate sustainability strategy. A generic strategy, which focuses on the selection of macro influencers, when the main objective is customer acquisition, can be described as transactional influencer marketing [99], with a less differentiated message content. In this case, the choice of strategy will be determined by the extent to which it will promote the transmission of emotions. Therefore the key decision-making factor will be the macro influencers potential in this area and the admiration they inspire. The second (addressed and differentiated) strategy requires the selection of micro influencers to convey the message to a more select and demanding niche market, and thus relies on market segmentation techniques. Here, the focus is on relationship marketing, customer retention, even when introducing a new product, which can target the brand's current customers. Nano influencers (between 1000 and 10,000 followers) can be very useful to brands aiming at the standard market [100]. The combined strategy is both more costly and more ambitious because it draws on both types of influencer. Here, the advantage of higher customer acquisition and retention potential must be weighed against higher resource costs and the risk of confusion if acquisition and retention goals are not properly balanced. Product characteristics can be an essential determinant of message effectiveness. For a highly exclusive product, the best choice is the combined strategy. For one that is less differentiated, an addressed strategy would be more appropriate.

This research has several limitations to stress. On the one hand, this is an exploratory study and does not confirm cause-effect relationships between the variables. It should be overcoming using confirmatory analysis, validating the measurement scales for the considered variables. Structural equation models serve this purpose. Particular attention needs to be paid to the measurement of customer engagement variable, due that it turning in a different variable depending on the influencer 
scenario. In these cases, multi-sample analyses with SEM would not be possible to implement, and the comparison between samples will have to be found using other methods. Additionally, employing probability rather than a convenience sample would permit generalized results. Moreover, some differences may arise depending on the cultural environment, for instance. Cultural differences can be very important when psychographic variables are being researched, so extending the geographic scope of the investigation to other countries would contribute to a wider understanding. On the other hand, the empirical model offers low explanatory power, which although usual in online behavioral intention [30], announces the need to include other variables in an extended model to obtain advanced knowledge in comparing the different types of influencers as determinants of customer engagement. Advanced models must also evaluate the dimensionality of certain variables of influencer characteristics, mainly credibility and engagement, that seem to be more predisposed as multidimensional. More research addressed to identifying criteria to select the most appropriate type of influencer for the company goals both financial and non-financial is needed. Furthermore, it would be interesting to consider other types of influencers such as free ambassadors, people moved by their sense of responsibility, who can be experts, professionals, and/or passionate people, with specific competencies in sustainability.

Author Contributions: All the authors collaborated in the development of all the parts of this work and in the paper elaboration with similar levels of effort. Specifically, C.B.-M. had focused on the theoretical background of the study and contributed interpreting the results and developing the discussion and conclusions of the paper. M.M.-N. performed the empirical study, applied the method and carried out the data analysis. All authors have read and agreed to the published version of the manuscript.

Funding: This research received no external funding.

Acknowledgments: The empirical work for this paper was also greatly facilitated by the group CREVALOR, supported by the DGA and the ESF, and co-funded by the European Investment Bank and the European Social Fund.

Conflicts of Interest: The authors declare no conflict of interest.

\section{References}

1. Bijen, Y.J. AD: The Effects of an Influencer, Comment and Product Combination on Brand Image. Master's Thesis, University of Twente, Enschede, The Netherlands, 2017. Available online: https://essay.utwente.nl/ 72265/2/BIJEN_MA_BMS.pdf (accessed on 11 April 2020).

2. Levin, A. Influencer Marketing for Brands: What YouTube and Instagram Can Teach You about the Future of Digital Advertising; Berkley: Spirit Lake, IA, USA, 2019.

3. Özsaçmacı, B.; Dursun, T. A Relationship Marketing Strategy in Brand Communication. In Impacts of Online Advertising on Business Performance; IGI Global: Hershey, PA, USA, 2020; pp. 52-80. [CrossRef]

4. Belanche, D.; Cenjor, I.; Pérez-Rueda, A. Instagram Stories versus Facebook Wall: An advertising effectiveness analysis. Span. J. Mark. (REIM-ESIC) 2019, 23, 69-94. [CrossRef]

5. Flavián, C.; Gurrea, R.; Orús, C. The effect of product presentation mode on the perceived content and continent quality of web sites. Online Inf. Rev. 2009, 33, 1103-1128. [CrossRef]

6. Wang, Z.; Kim, H.G. Can Social Media Marketing Improve Customer Relationship Capabilities and Firm Performance? Dynamic Capability Perspective. J. Interact. Mark. 2017, 39, 15-26. [CrossRef]

7. De Veirman, M.; Cauberghe, V.; Hudders, L. Marketing through Instagram influencers: The impact of number of followers and product divergence on brand attitude. Int. J. Advert. 2017, 36, 1-31. [CrossRef]

8. Curiel, C.; Clavijo, L. Comunicación y Social Media en las Empresas de Moda: Asos Como Caso de Estudio; Universidad de Sevilla: Seville, Spain, 2017; pp. 226-258.

9. Steinhoff, L.; Arli, D.; Weaven, S.; Kozlenkova, I.V. Online relationship marketing. J. Acad. Mark. Sci. 2018, 47, 369-393. [CrossRef]

10. Hanna, R.; Rohm, A.; Crittenden, V.L. We are all connected: The power of the social media ecosystem. Bus. Horiz. 2011, 54, 265-273. [CrossRef]

11. Rainie, L. A Biography of the Pew Research Center's Internet \& American Life Project. Encyclopedia Cyber Behav. 2012, 25-41. [CrossRef] 
12. Berthon, P.; Pitt, L.F.; Plangger, K.; Shapiro, D. Marketing meets Web 2.0, social media, and creative consumers: Implications for international marketing strategy. Bus. Horiz. 2012, 55, 261-271. [CrossRef]

13. Casalo, L.V.; Flavián, C.; Ibáñez-Sánchez, S. Influencers on Instagram: Antecedents and consequences of opinion leadership. J. Bus. Res. 2018. [CrossRef]

14. IAB. Estudio anual de redes sociales. Madrid. 2019. Available online: https://iabspain.es/download/24717/ (accessed on 22 November 2019).

15. Marinucci, J. Five Social Media trends that Will Impact Digital Advertising. 2018. Available online: https://www.forbes.com/sites/forbesagencycouncil/2018/09/14/five-social-media-trends-that-willimpact-digital-advertising/\#23fb222e2f05 (accessed on 22 November 2019).

16. Voorveld, H.A.M.; Van Noort, G.; Muntinga, D.G.; Bronner, F. Engagement with Social Media and Social Media Advertising: The Differentiating Role of Platform Type. J. Advert. 2018, 47, 38-54. [CrossRef]

17. Pikas, B.; Sorrentino, G. The effectiveness of online advertising: Consumer's perceptions of ads on Facebook, Twitter and YouTube. J. Appl. Bus. Econ. 2014, 16, 70-81.

18. Trainor, K.; Andzulis, J.; Rapp, A.; Agnihotri, R. Social media technology usage and customer relationship performance: A capabilities-based examination of social CRM. J. Bus. Res. 2014, 67, 1201-1208. [CrossRef]

19. Rezaee, Z. Corporate sustainability: Theoretical and integrated strategic imperative and pragmatic approach. J. Bus. Inq. 2017, 16, 60-87.

20. Gupta, S.; Kumar, V. Sustainability as corporate culture of a brand for superior performance. J. World Bus. 2013, 48, 311-320. [CrossRef]

21. Alshehhi, A.; Nobanee, H.; Khare, N. The Impact of Sustainability Practices on Corporate Financial Performance: Literature Trends and Future Research Potential. Sustainability 2018, 10, 494. [CrossRef]

22. Valentini, C.; Romenti, S.; Murtarelli, G.; Pizzetti, M. Digital visual engagement: Influencing purchase intentions on Instagram. J. Commun. Manag. 2018, 22, 362-381. [CrossRef]

23. Polaino, R.C.; Villar-Cirujano, E.; Martín-Cárdaba, M. Ángel Artivism and NGO: Relationship between image and 'engagement' in Instagram. Comunicar 2018, 26, 29-38. [CrossRef]

24. Cohen, E.H. Brand sustainability index. J. Retail. Consum. Serv. 2016, 29, 114-122.

25. Baalbaki, S.; Guzmán, F.; Baalbaki, F.G.S. A consumer-perceived consumer-based brand equity scale. J. Brand Manag. 2016, 23, 229-251. [CrossRef]

26. Kang, M.Y.; Park, B. Sustainable Corporate Social Media Marketing Based on Message Structural Features: Firm Size Plays a Significant Role as a Moderator. Sustainability 2018, 10, 1167. [CrossRef]

27. Johnstone, L.; Lindh, C. The sustainability-age dilemma: A theory of (un)planned behaviour via influencers. J. Consum. Behav. 2017, 17, e127-e139. [CrossRef]

28. Chwialkowska, A. How sustainability influencers drive green lifestyle adoption on social media: The process of green lifestyle adoption explained through the lenses of the minority influence model and social learning theory. Manag. Sustain. Dev. 2019, 11, 33-42. [CrossRef]

29. Sokolova, K.; Kefi, H. Instagram and YouTube bloggers promote it, why should I buy? How credibility and parasocial interaction influence purchase intentions. J. Retail. Consum. Serv. 2020, 53, 1-9. [CrossRef]

30. Boerman, S.C. The effects of the standardized instagram disclosure for micro- and meso-influencers. Comput. Hum. Behav. 2020, 103, 199-207. [CrossRef]

31. Calderon, E.; Sanz, I.P.; Huerta-Zavala, P. Economic Sustainability in Franchising: A Model to Predict Franchisor Success or Failure. Sustainability 2017, 9, 1419. [CrossRef]

32. Northouse, P. Leadership: Theory and Practice, 4th ed.; Sage: Thousand Oaks, CA, USA, 2007.

33. Middlebrooks, A.; Miltenberger, L.; Tweedy, J.; Newman, G.; Follman, J. Developing a sustainability ethic in leaders. J. Leadersh. Stud. 2009, 3, 31-43. [CrossRef]

34. Ulrich, D.; Smallwood, N. Leadership Sustainability. Lead. Lead. 2013, 2013, 32-38. [CrossRef]

35. Gallagher, K. The Influencer Marketing Report: Research, strategy \& platforms for leveraging social media influencers. Bus. Insider 2018. Available online: https://www.businessinsider.com/the-influencer-marketingreport-2018-1 (accessed on 15 January 2020).

36. Conick, H. How to Win Friends and Influence Millions: The Rules of Influencer Marketing. Mark. News 2018, 52, 36-45.

37. Morgan, R.M.; Hunt, S.D. The commitment-trust theory of relationship marketing. J. Mark. 1994, 58, $20-38$. [CrossRef] 
38. Perez, C.; Luque, S. Fashion influence marketing. Study of the new model of consumption in Instagram of university millennials. adComunica 2018, 15, 255-281. [CrossRef]

39. Bolton, R.N. Comment: Customer engagement: Opportunities and challenges for organizations. J. Serv. Res. 2011, 14, 272-274. [CrossRef]

40. Van Doorn, J.; Lemon, K.N.; Mittal, V.; Nass, S.; Pick, D.; Pirner, P.; Verhoef, P.C. Customer Engagement Behavior: Theoretical Foundations and Research Directions. J. Serv. Res. 2010, 13, 253-266. [CrossRef]

41. Kumar, V.; Aksoy, L.; Donkers, B.; Venkatesan, R.; Wiesel, T.; Tillmanns, S. Undervalued or Overvalued Customers: Capturing Total Customer Engagement Value. J. Serv. Res. 2010, 13, 297-310. [CrossRef]

42. Vivek, S.D.; Beatty, S.E.; Morgan, R.M. Customer Engagement: Exploring Customer Relationships Beyond Purchase. J. Mark. Theory Pr. 2012, 20, 122-146. [CrossRef]

43. Pansari, A.; Kumar, V. Customer engagement: The construct, antecedents, and consequences. J. Acad. Mark. Sci. 2016, 45, 294-311. [CrossRef]

44. McKinsey \& Company. The Consumer Decision Journey. Available online: https://www.mckinsey.com/ business-functions/marketing-and-sales/our-insights/the-consumer (accessed on 22 November 2018).

45. Mediakix. Influencer Marketing 2019 Industry Benchmarks. 2019. Available online: https://mediakix.com/ influencer-marketing-resources/influencer-marketing-industry-statistics-survey-benchmarks/ (accessed on 10 April 2020).

46. Statista. Statista Dossier on Influencer Marketing in the United States and Worldwide. 2018. Available online: https://www.statista.com/study/28362/influence-marketing-statista-dossier/ (accessed on 10 March 2020).

47. Geurin-Eagleman, A.N.; Burch, L.M.; Geurin, A. Communicating via photographs: A gendered analysis of Olympic athletes' visual self-presentation on Instagram. Sport Manag. Rev. 2016, 19, 133-145. [CrossRef]

48. Osman, M. 20+ Mind-Blowing Instagram Stats and Facts By Maddy Osman. 2019. Available online: https://kinsta.com/blog/instagram-stats/ (accessed on 23 October 2019).

49. Leibowitz, B. Instagram vs Facebook: Which Can Boost Your Business More? 2018. Available online: www.dreamgrow.com/instagram-facebook-advertising/ (accessed on 22 November 2019).

50. Kim, D.H.; Seely, N.K.; Jung, J.-H. Do you prefer, Pinterest or Instagram? The role of image-sharing SNSs and self-monitoring in enhancing ad effectiveness. Comput. Hum. Behav. 2017, 70, 535-543. [CrossRef]

51. Hidayati, S.C.; Chen, Y.L.; Yang, C.L.; Hua, K.L. Popularity meter: An influence-and aesthetics-aware social media popularity predictor. In Proceedings of the 2017 ACM on Multimedia Conference, Silicon Valley, CA, USA, 23-27 October 2017; ACM: New York, NY, USA, 2017; pp. 1918-1923.

52. Chen, J.H.; Fu, J.-R. On the effects of perceived value in the mobile moment. Electron. Commer. Res. Appl. 2018, 27, 118-128. [CrossRef]

53. Bashir, A.; Wen, J.; Kim, E.; Morris, J.D. The Role of Consumer Affect on Visual Social Networking Sites: How Consumers Build Brand Relationships. J. Curr. Issues Res. Advert. 2018, 39, 178-191. [CrossRef]

54. Bergström, T.; Bäckman, L. Marketing and PR in social media: How the Utilization of Instagram Builds and Maintains Customer Relationships. 2013. Available online: http://www.diva-portal.org/smash/get/diva2: 625012/FULLTEXT01.pdf (accessed on 29 March 2020).

55. RhythmOne Influencer Marketing Benchmark Report Full Year 2015. 2015. Available online: https: //www.rhythmone.com/rhythmbuzz/insights/2015influencerbenchmarks-report (accessed on 28 October 2019).

56. Guidara, M. Las 10 Estadísticas de Instagram que tienes que tener en cuenta sí o sí para planificar tu estrategia 2018. 2018. Available online: https:/postcron.com/es/blog/estadisticas-de-instagram/ (accessed on 22 November 2018).

57. Wong, K. The Explosive Growth of Influencer Marketing and What It Means for You. 2014. Available online: http://www.forbes.com/sites/kylewong/2014/09/10/the-explosive-growth-of-influencer-marketingand-what-it-eans-for-you/\#660f82d4595f (accessed on 26 February 2016).

58. Influencer Marketing Hub El Estado del Marketing de Influencers 2019: Informe Benchmark (+ Infográfico). Available online: https://influencermarketinghub.com/es/informe-bechmark-marketing-de-influencers-2019/ (accessed on 22 March 2020).

59. Edell, J.A.; Burke, M.C. The Power of Feelings in Understanding Advertising Effects. J. Consum. Res. 1987, 14, 421. [CrossRef]

60. Yilmaz, C.; Telci, E.E.; Bodur, M.; Iscioglu, T.E. Source characteristics and advertising effectiveness: The roles of message processing motivation and product category knowledge. Int. J. Advert. 2011, 30, 889. [CrossRef] 
61. Jin, S.V.; Phua, J. Following Celebrities' Tweets About Brands: The Impact of Twitter-Based Electronic Word-of-Mouth on Consumers' Source Credibility Perception, Buying Intention, and Social Identification With Celebrities. J. Advert. 2014, 43, 181-195. [CrossRef]

62. McLaughlin, C. Source Credibility and Consumers' Responses to Marketer Involvement in Facebook Brand Communities: What Causes Consumers to Engage? J. Interact. Advert. 2016, 16, 101-116. [CrossRef]

63. Interactive. Marketing Digital Web. Available online: https://interactivadigital.com/formacion-y-estudiosmarketing-digital/10-cualidades-de-un-buen-influencer/ (accessed on 20 September 2019).

64. Glucksman, M. The rise of social media influencer marketing on lifestyle branding: A case study of Lucie Fink. Elon J. Undergrad. Res. Commun. 2017, 8, 77-87.

65. Phillips, B.; Lee, W.-N. Interactive Animation: Exploring Spokes-Characters on the Internet. J. Curr. Issues Res. Advert. 2005, 27, 1-17. [CrossRef]

66. Arora, R.; Stoner, C.; Arora, A. Using framing and credibility to incorporate exercise and fitness in individuals' lifestyle. J. Consum. Mark. 2006, 23, 199-207. [CrossRef]

67. Goldsmith, R.E.; Lafferty, B.A.; Newell, S.J. The Impact of Corporate Credibility and Celebrity Credibility on Consumer Reaction to Advertisements and Brands. J. Advert. 2000, 29, 43-54. [CrossRef]

68. Sanders, T. The Likeability Factor: How to Boost Your L-Factor and Achieve Your Life's Dreams; Crown Business: New York, NY, USA, 2006.

69. Callcott, M.F.; Phillips, B.J. Observations: Elves make good cookies: Creating likeable spokes-character advertising. J. Advert. Res. 1996, 36, 73-79.

70. Coss, Y. Micro vs Macro Influencers: ¿cuál es el más indicado? 2018. Available online: https://blog. digimind.com/es/insight-driven-marketing/micro-vs-macro-influencers-cual-es-el-mas-indicado (accessed on 22 November 2018).

71. Munera, I. El Mundo. 2019. Available online: https://www.elmundo.es/economia/ahorro-y-consumo/2019/ 01/06/5c051502fdddff3d128b4646.html (accessed on 25 November 2019).

72. Utz, S. Show me your friends and I will tell you what type of person you are: How one's profile, number of friends, and type of friends influence impression formation on social network sites. J. Comput. Commun. 2010, 15, 314-335. [CrossRef]

73. Graham, G.S. More Than friends: Popularity on Facebook and its role in impression formation. J. Comput. Mediat. Commun. 2014, 19, 358-372.

74. Kelman, H.C.; Hovland, C.I. "Reinstatement" of the communicator in delayed measurement of opinion change. J. Abnorm. Soc. Psychol. 1953, 48, 327-335. [CrossRef] [PubMed]

75. Applbaum, R.L.; Anatol, K.W.E. Dimensions of source credibility: A test for reproducibility. Speech Monogr. 1973, 40, 231-237. [CrossRef]

76. Freedman, J.L.; Sears, D.O.; Carlsmith, M.J. Social Psychology; Prentice Hall: Englewood, NJ, USA, 1981.

77. Ohanian, R. Construction and Validation of a Scale to Measure Celebrity Endorsers' Perceived Expertise, Trustworthiness, and Attractiveness. J. Advert. 1990, 19, 39-52. [CrossRef]

78. Eagly, A.H.; Chaiken, S. An attribution analysis of the effect of communicator characteristics on opinion change: The case of communicator attractiveness. J. Pers. Soc. Psychol. 1975, 32, 136-144. [CrossRef]

79. Belch, G.E.; Belch, M.A. Introduction to Advertising and Promotion: An Integrated Marketing Communications Perspective; Irwin: Homewood, IL, USA, 1993.

80. Lafferty, B.A.; Goldsmith, R.E. Corporate Credibility's Role in Consumers' Attitudes and Purchase Intentions When a High versus a Low Credibility Endorser Is Used in the Ad. J. Bus. Res. 1999, 44, 109-116. [CrossRef]

81. Mizerski, R.W.; Golden, L.L.; Kernan, J.B. The Attribution Process in Consumer Decision Making. J. Consum. Res. 1979, 6, 123. [CrossRef]

82. Liu, S.; Jiang, C.; Lin, Z.; Ding, Y.; Duan, R.; Xu, Z. Identifying effective influencers based on trust for electronic word-of-mouth marketing: A domain-aware approach. Inf. Sci. 2015, 306, 34-52. [CrossRef]

83. Pornpitakpan, C. The Persuasiveness of Source Credibility: A Critical Review of Five Decades' Evidence. J. Appl. Soc. Psychol. 2004, 34, 243-281. [CrossRef]

84. Anderson, M. What Are Micro-INFLUENCERS and Why Are They so Effective? 2019. Available online: https://www.impactbnd.com/blog/power-of-micro-influencers (accessed on 15 March 2020).

85. Djafarova, E.; Trofimenko, O. 'Instafamous'-Credibility and self-presentation of micro-celebrities on social media. Inf. Commun. Soc. 2018, 22, 1432-1446. [CrossRef] 
86. Batra, R.; Ray, M.L. Affective Responses Mediating Acceptance of Advertising. J. Consum. Res. 1986, 13, 234. [CrossRef]

87. Gallup Consulting. Customer engagement: The Customer Side of the Human Sigma Equation. 2010. Available online: http://eu.gallup.com/Consulting/118180/Customer-Engagement.aspx (accessed on 22 October 2018).

88. Sashi, C. Customer engagement, buyer-seller relationships, and social media. Manag. Decis. 2012, 50, $253-272$. [CrossRef]

89. Whalar Influencer Marketing Agency. Available online: https://www.thedrum.com/news/2019/06/18/ influencer-ads-more-emotionally-intense-and-memorable-tv-claims-neuroscience-study (accessed on 20 April 2020).

90. Gustafsson, A.; Johnson, M.D.; Roos, I. The Effects of Customer Satisfaction, Relationship Commitment Dimensions, and Triggers on Customer Retention. J. Mark. 2005, 69, 210-218. [CrossRef]

91. Guttentag, D.; Smith, S.; Potwarka, L.; Havitz, M. Why Tourists Choose Airbnb: A Motivation-Based Segmentation Study. J. Travel Res. 2017, 57, 342-359. [CrossRef]

92. Ferran, C. The Effects of Videoconferencing on Persuasion. Ph.D. Thesis, Boston University, Boston, MA, USA, 2000.

93. Whittler, T.E.; Dimeo, J. Viewer's reaction to racial cues in advertising stimuli. J. Advert. Res. 1991, 31, 37-46.

94. Lou, C.; Yuan, S. Influencer Marketing: How Message Value and Credibility Affect Consumer Trust of Branded Content on Social Media. J. Interact. Advert. 2019, 19, 58-73. [CrossRef]

95. Pike, S. Destination image analysis-A review of 142 papers from 1973 to 2000. Tour. Manag. 2002, 23, 541-549. [CrossRef]

96. T,ugulea, O. City Brand Personality-Relations with Dimensions and Dimensions Inter-Relations. Sustainability 2017, 9, 2243. [CrossRef]

97. Joreskog, K.G. Statistical analysis of sets of congeneric tests. Psychometrika 1971, 36, 109-133. [CrossRef]

98. Nunnally, J.C. Teoría Psicométrica; Editorial Trillas: Mexico City, Mexico, 1987.

99. Northman, N. Sideqik. 2020. Available online: https://www.sideqik.com/influencer-marketing/relationshipbased-influencer-marketing (accessed on 1 April 2020).

100. Traackr. Available online: https://www.traackr.com/resources/influencer-marketing (accessed on 3 February 2020). 